\title{
Suitability of Sugar Cane Bagasse Ash as a Replacement for Cement in Concrete
}

\author{
Adejoh B.O ${ }^{1}$, Pogu J.H ${ }^{2}$ and Jafar $\mathrm{I}^{3}$. \\ Department of Civil Engineering, Kaduna Polytechnic
}

Nigeria

\begin{abstract}
This study is aimed at investigating the compressive strength of concrete using Sugarcane Bagasse Ash (SCBA) as a replacement for cement in concrete using two grades of concrete; grade 20, and 30 respectively. Sugarcane bagasse ash is the waste product of the combustion of bagasse for energy in sugar factories and is also by-products of agricultural waste, sugar cane bagasse ash are disposed of in the landfill and are now becoming an environmental concern. The concrete cube cast was; control (0\%) $2 \%$, $4 \%, 6 \%$ and $8 \%$ respectively, the cube was cast, cured and tested at 7days, 14days, and 28days. Although the results of this study have shown a significant reduction in compressive strength of concrete utilizing SCBA than normal concrete, it can be concluded that optimum amount of sugarcane bagasse ash that can be replaced with cement is $6 \%$ by weight without any admixtures.
\end{abstract}

Keywords: Cementious material, Compressive strength, Concrete, Sugarcane Bagasse ash, Pozzolana.

\subsection{INTRODUCTION}

Concrete is the most commonly used construction material in the world. It is basically composed of two components: paste and aggregate. The paste contains cement and water and sometimes other cementitious and chemical admixtures, whereas the aggregate contains sand and gravel or crushed stone, Lavanya M.R (2012). The paste binds the aggregates together, the aggregates are relatively inert filler materials which occupy $70 \%$ to $80 \%$ of the concrete and can therefore be expected to have influence on its properties. The proportions of these components, the paste and the aggregate is controlled by; the strength and durability of the desired concrete, the workability of the fresh concrete and the cost of the concrete. Cement which is one of the components of concrete plays a great role, but is the most expensive and environmentally unfriendly material. Ordinary Portland cement is the most extensively used construction material in the world. Since the early 1980's, there has been an enormous demand for the mineral admixture and in future this demand is expected to increase even more also in this modern age, every structure has its own intended purpose and hence to meet this purpose, modification in traditional cement concrete has become essential. Therefore requirements for economical and more environmental-friendly cementing materials have extended interest in other cementing materials that can be used as partial replacement of the normal Portland cement, BirukHailu (2011). Ground granulated blast furnace slag, fly ash; silica fume, etc. have been used successfully for this purpose. Sugarcane Bagasse Ash (SCBA) which is a byproduct of sugar factories found after burning sugarcane bagasse is being produced from sugar manufacturing units as a waste material which will be grinded to the fineness less than cement for obtaining good bonding between cement and SCBA. Recently, sugarcane bagasse ash, has been tested in some parts of the world for its pozzolanic property and has been found to improve some of the properties of the concrete like compressive strength and water tightness in certain replacement percentages and fineness, Ranjith A. and Sanjith J. (2015). The use of sugarcane bagasse ash (SCBA) as cement replacement material is to improve quality and reduce the cost of construction material such as mortar and concrete pavers. Hence, several research groups, and even the Portland cement industry, are investigating alternatives to produce green binding materials. Moreover, these binding materials can reduce up to $80 \%$ of $\mathrm{CO} 2$ emissions when compared to that of Portland cement production. The release of dust, gases, noise and vibration when operating machinery and during blasting in quarries and consumption of large quantities of fuel during manufacture is a form of airborne pollution. Therefore, there is the need to search for local materials as alternatives for the construction of functional but low cost buildings in both the rural and urban areas. The important of this research is to help reduce the cost of cement and reduce the volume of solid waste generated from sugarcane. This will economize the usage of Portland cement in construction works, Lourdes Soriano (2013). Nowadays, several studies have been performed in order to re-use 
industrial and/or agricultural wastes abundantly generated in society: this approach is in agreement with sustainable development principles.

\subsection{MATERIAL AND METHOD}

\subsection{Bagasse Ash}

Bagasse is a cellulose fiber remaining after the extraction of the sugar-bearing juice from sugarcane. Bagasse ash is one of the biomass sources and valuable byproducts in sugar milling that often uses bagasse as a primary fuel source to supply all the needs of energy to move the plants. The bagasse ash is about $8-10 \%$ of the bagasse and contains unburned matter, silica and alumina. Kanchan L. (2013).

Bagasse ash has been a problem to the environment due to its disposal. The most significant pollutant emitted from the boilers being a particulate matter, caused by the turbulent movement of combustion gases with respect to the burning bagasse and resulting ash. Sometimes some auxiliary fuels typically fuel or natural gas may be used during startup of the boiler or when the moisture content of the bagasse is too high to support combustion, in such cases the emissions of $\mathrm{SO}_{2}$ and $\mathrm{NOX}$ will increase. Ghazali M.J (2008).

Table.1: Chemical Composition of Sugarcane Bagasse Ash

\begin{tabular}{|c|c|c|}
\hline S/NO & Compounds & Weights \\
\hline 1 & $\mathrm{SiO} 2$ & 85.55 \\
\hline 2 & $\mathrm{Al}_{2 \mathrm{O} 3}$ & 2.29 \\
\hline 3 & $\mathrm{Fe}_{203}$ & 1.21 \\
\hline 4 & $\mathrm{TiO} 2$ & 0.20 \\
\hline 5 & $\mathrm{~K}_{20}$ & 1.33 \\
\hline 6 & $\mathrm{SO}_{3}$ & 2.28 \\
\hline 7 & $\mathrm{C}_{\mathrm{a}} \mathrm{O}$ & 4.05 \\
\hline 8 & $\mathrm{P} 2 \mathrm{O} 5$ & 3.01 \\
\hline 9 & $\mathrm{M}_{\mathrm{n}} \mathrm{O}$ & 0.08 \\
\hline
\end{tabular}

Sources: Biruk Hailu (2011)

Table.2: Characteristics of Sugarcane Bagasse Ash

\begin{tabular}{|l|l|l|}
\hline S/NO & Characteristics & Value \\
\hline 1 & Colour & Black \\
\hline 2 & Particle density (g/cm3) & 2.39 \\
\hline 3 & Organic matter $(\%)$ & 10.32 \\
\hline 4 & Clay (\%) & 0.70 \\
\hline 5 & Silt $(\%)$ & 11.50 \\
\hline 6 & Sand & 87.80 \\
\hline
\end{tabular}

Sources: Biruk Hailu (2011)

\subsection{Materials}

The cement used for this work was bought from a cement deport at pan taker market Tudun Wada, while the fine and coarse aggregates were obtained from kabala junction, Kaduna state. The sugarcane bagasse was collected from Kawo market, Asikolaye junction and Hayin Danmani, in Kaduna north, Kaduna state. The materials were transported to the laboratory where it was dried and kept in safe conditions.

\subsection{Compressive test of Concrete}

Compressive strength of concrete cube test provides an idea about all the characteristics of concrete. By this single test, one can judge whether concreting has been done properly or not. Compressive strength of concrete depends on many factors such as water-cement ratio, cement strength, quality of concrete material, and quality control during production of concrete etc. The test 
for compressive strength is carried out either on cube or on cylinder. Various standard codes recommend concrete cylinder or concrete cube as the standard specimen for the test. In the research, standard concrete cube of $150 \mathrm{~mm} \times 150 \mathrm{~mm} \times 150 \mathrm{~mm}$ was used.

This concrete is poured in the mould and tamped properly so as not to have any voids. After 24 hours these moulds are removed and the test specimens are put in water for curing. The top surface of these specimens should be made even and smooth. It is done by putting cement paste and spreading smoothly on the whole area of specimen. These specimens are tested by compression testing machine after 7 days curing or 28 days curing. Load are applied gradually until the test specimen fails in compression.

\subsection{RESULTS AND DISCUSSION}

Table.3: Compressive Strength of Control, 2\%, 4\%, $6 \%$ and $8 \%$ (Grade 20)

\begin{tabular}{|c|c|c|c|c|c|}
\hline \multirow{2}{*}{ Age (Days) } & \multicolumn{5}{|c|}{ Crushing strength (N/mm $\left.{ }^{2}\right)$} \\
\cline { 2 - 6 } & Control & $\mathbf{2 \%}$ Repl. & $\mathbf{4 \%}$ Repl. & 6\% Repl. & 8\% Repl. \\
\hline 7 & 18.08 & 17.71 & 16.16 & 14.84 & 13.56 \\
\hline 14 & 21.01 & 19.68 & 18.50 & 17.17 & 15.63 \\
\hline 28 & 25.33 & 22.97 & 21.96 & 20.88 & 16.77 \\
\hline
\end{tabular}

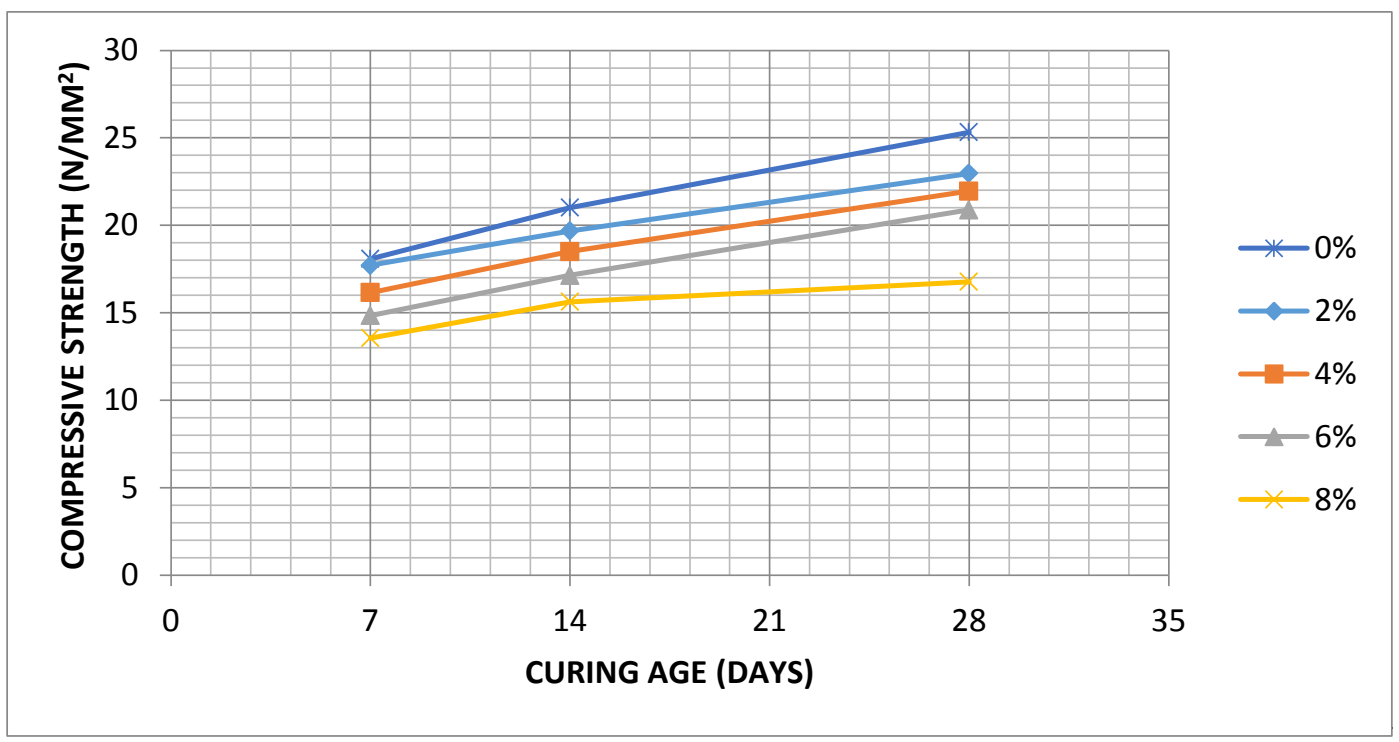

Fig. 1: A graph of compressive strength (N/mm²) against Age (Days) for Grade 20

Table.4: Compressive Strength of Control, $2 \%, 4 \%, 6 \%$ and $8 \%$ (Grade 30 )

\begin{tabular}{|c|c|c|c|c|c|}
\hline \multirow{2}{*}{ Age (Days) } & \multicolumn{5}{|c|}{ Crushing strength (N/mm ${ }^{2}$ ) } \\
\cline { 2 - 6 } & Control & $\mathbf{2 \%}$ Repl. & $\mathbf{4 \%}$ Repl. & 6\% Repl. & 8\% Repl. \\
\hline 7 & 22.55 & 19.69 & 16.90 & 15.42 & 13.89 \\
\hline 14 & 28.97 & 26.95 & 25.36 & 24.12 & 22.89 \\
\hline 28 & 35.93 & 32.19 & 31.01 & 30.19 & 28.98 \\
\hline
\end{tabular}




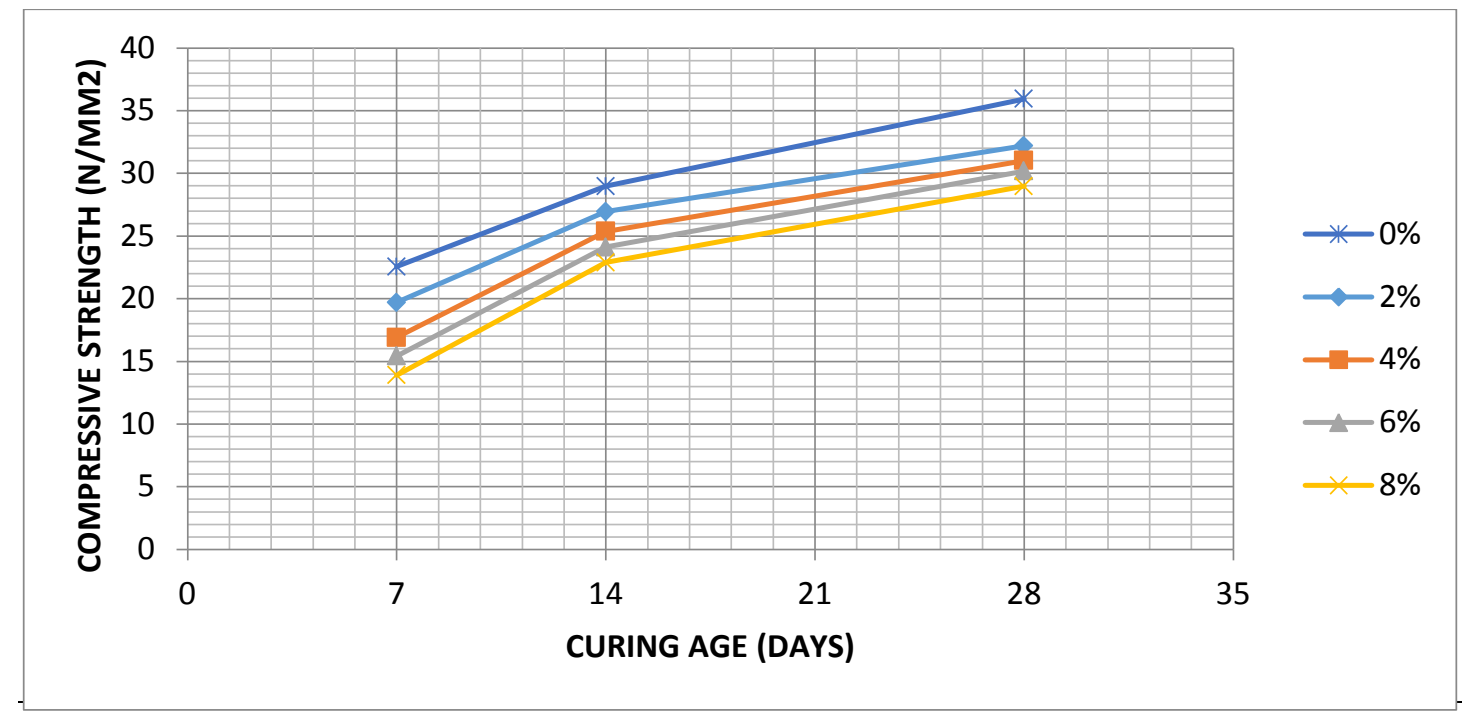

Fig. 1: A graph of compressive strength (N/mm ${ }^{2}$ ) against Age (Days) for Grade 30

The results of Compressive Strength for $0 \%, 2 \%, 4 \%, 6 \%$ and $8 \%$ replacements for Grades 20 and 30 concretes are as follows: For Grade 20 at 7, 14 and 28 days, $0 \%$ mix: $18.08 \mathrm{~N} / \mathrm{mm}^{2}, 21.01 \mathrm{~N} / \mathrm{mm}^{2}$ and $25.33 \mathrm{~N} / \mathrm{mm} 2$, for $2 \%$ replacement: $17.71 \mathrm{~N} / \mathrm{mm}^{2}$, $19.68 \mathrm{~N} / \mathrm{mm}^{2}$ and $22.97 \mathrm{~N} / \mathrm{mm} 2$, for $4 \%$ replacement: $16.16 \mathrm{~N} / \mathrm{mm}^{2}, 18.50 \mathrm{~N} / \mathrm{mm}^{2}$ and $21.96 \mathrm{~N} / \mathrm{mm} 2,6 \%$ replacement: 14.84 $\mathrm{N} / \mathrm{mm}^{2}, 17.14 \mathrm{~N} / \mathrm{mm}^{2}$, and $20.88 \mathrm{~N} / \mathrm{mm} 2$, for $8 \%$ replacement: $13.56 \mathrm{~N} / \mathrm{mm}^{2}, 15.63 \mathrm{~N} / \mathrm{mm}^{2}$ and $16.77 \mathrm{~N} / \mathrm{mm} 2$. For Grade 30 at 7 , 14 , and 28 days, the results are, for $0 \%$ mix: $22.55 \mathrm{~N} / \mathrm{mm}^{2}, 28.97 \mathrm{~N} / \mathrm{mm}^{2}$, and $35.93 \mathrm{~N} / \mathrm{mm} 2,2 \%$ replacement: $19.69 \mathrm{~N} / \mathrm{mm}^{2}$, $26.95 \mathrm{~N} / \mathrm{mm}^{2}$, and $32.19 \mathrm{~N} / \mathrm{mm} 2,4 \%$ replacement: $16.90 \mathrm{~N} / \mathrm{mm}^{2}, 25.36 \mathrm{~N} / \mathrm{mm}^{2}$ and $31.01 \mathrm{~N} / \mathrm{mm} 2,6 \%$ replacement: 15.42 $\mathrm{N} / \mathrm{mm}^{2}, 24.12 \mathrm{~N} / \mathrm{mm}^{2}$ and $30.19 \mathrm{~N} / \mathrm{mm} 2,8 \%$ replacement: $13.89 \mathrm{~N} / \mathrm{mm}^{2}, 22.89 \mathrm{~N} / \mathrm{mm}^{2}$ and $28.98 \mathrm{~N} / \mathrm{mm} 2$ respectively.

Therefore, the results above shows that, as the percentage of replacement increases, the strength of concrete for both grades 25 and 35 decrease as well, but as the curing day increases, the strength of the concrete also increases.

The results of this trend may be due to a drop in workability with increase SCBA. Test to assess the workability of fresh concrete indicates that incorporation of SCBA in concrete leads to a decrease in slump value, which depends on the SCBA content. This reduction in slump was due to the absorption of some quantity of mixing water by SCBA particles.

Because of the large surface area of SCBA, more water molecules were attracted towards the surface of these particles. Thus, the quantity of the free water available for the concrete mix which helps in improving the fluidity of the mixture was decreased and there was an increase in the viscosity of the concrete mix. This in turn reduces the workability of the concrete and the effect was the same for other two tests also. If density were to be considered according to BS877, the concrete using SCBA would have been considered a light-weight concrete.

\subsection{CONCLUSION}

It can be seen that there is a slight decrease in strength of concrete with increase in percentage replacement of SCBA, though there is an increase in strength with increase in curing days. Despite the observed changes in compressive strength of the concrete due to percentage replacements, there is a large market for concrete products in which addition of SCBA would be feasible. These can also include primary structural applications of medium to low strength requirements, benefiting from other features of this type of concrete. Therefore, the use of SCBA can still be employed in concrete production as partial replacement for cement since the strength gained are effective according to BS 812 , but this can only be achieved with longer days of curing.

\section{RECOMMENDATIONS}

Although, the results of this study have shown a significant reduction in compressive strength of concrete utilizing SCBA than normal concrete, it could be recommended that SCBA concrete should be used in road curbs, concrete blocks, non-bearing concrete walls, precast units (partition walls, concrete blocks for Architectural applications and some cases of slabs on soil, culverts, sidewalks, drive ways), foundation pads for machinery, etc. It is here by recommended that further study should be carried out under proper supervision on the SCBA in concrete by the addition of admixtures such as silica fume and sodium hydroxide at different percentage in other to overcome the significant reduction of concrete strength due to replacement with SCBA. 


\section{REFERENCES}

1. Asma Abd Elhameed Hussein et al., "Compressive Strength and Microstructure of Sugar Cane Bagasse Ash Concrete"

2. Biruk Hailu and Abebe Dinku (2011) "Application of sugarcane bagasse ash as a partial cement replacement material"

3. B. Madhusudhana Reddy et al., "Effect of Hydrochloric Acid on Blended cement and silica fume blended cement and their concretes", International journal of science and technology volume 1 no. 9, September, 2012

4. Beulah M. Asst Professor, Prahallada M. C. Professor, "Effect of replacement of cement by metakalion on the properties of high performance concrete

5. G. Siva Kumar et al., "Preparation of Bio-Cement using SCBH and its Hydration Behavior".

6. H.S Otuoze et al., "Characterization of SCBH and ordinary Portland cement blends in concrete".

7. Kanchan lata Singh and S.M Ali Jawaid, (August 2013), "Utilization of sugarcane bagasse ash (SCBA) as pozzolanic material in concrete".

8. Kawade U.R. et al., "Effect of use of bagasse ash on strength of concrete", International journal of innovative research in science, Engineering and technology.(July 2013)

9. Lavanya M.R et al., (2012). "An Experimental study on the compressive strength of concrete by partial replacement of cement with SCBA".

10. Lourdes M.S Souza et al., "Hydration study of SCBA and Calcium Hydroxide pastes of various initial C/S ratios".

11. Murthi P. and V. Siva Kumar, "Studies on Acid Resistance of Ternary Blended concrete", Asia journal of civil engineering (building and housing) Vol.9, No.5 (2008).

12. Paul R. Lohlia and Ramesh C. Joshi, "Concrete Admixture Hand Book"

13. Piyanut Muangtong et al., "Effect of Fine Bagasse Ash on Workability and Compressive Strength of Mortars".

14. Srinivasan Rao et al., "Durability studies on steel fibre reinforced metakaolin blended concrete".

15. V.S Ramachandran et al., "Concrete Admixture Hand Book".

16. Vijaya M. Sekhar Reddy, I.V.Ramana Reddy, "Studies on durability characteristics Of high performance concrete" International journal of advanced scientific and technical research, issue 2 volume 6, December 2012 ISS 2249-9954. 